\title{
How can the integrity of occupational and environmental health research be maintained in the presence of conflicting interests?
}

Xaver Baur ${ }^{1 *}$ (D, Colin L. Soskolne ${ }^{2,3}$ and Lisa A. Bero ${ }^{4}$

\begin{abstract}
Background: The sciences, and especially the research subspecialties of occupational and environmental health, are being misused. The misuse serves to interfere with the advancement of policies that depend on rational evidence needed for policies to protect public health.

Methods: We selectively surveyed the independent scientific literature. In addition, the efforts of respected international professional organizations of scientists whose focus is on maintaining and improving public health have been considered. This commentary is unique in assembling not only the factual basis for sounding alarms about significant bias in occupational and environmental health research, but also about the manipulative mechanisms used, and, in turn, the methods needed to keep science honest.
\end{abstract}

Results: Scientific integrity is based on the principle that research is conducted as objectively as possible; it cannot be compromised by special interests whose primary goals are neither to seek truth nor to protect human health. Evidence demonstrates a significant risk of bias in research reports sponsored by financial interests. Practices of corporate malfeasance include the orchestrated contamination of editorial boards of peer-reviewed scientific journals with industry apologists; interference with activities of national regulatory bodies and international review panels engaged in safeguarding occupational and public health; constructing roadblocks by capitalizing on uncertainty to undermine scientific consensus for much-needed government regulation of carcinogenic, endocrinedisrupting and/or immunotoxic agents; promoting "causation" criteria that lack foundation and effectively block workers' access to legal remedies for harms from occupational exposures resulting in morbidity and premature mortality; and, violating standards of professional conduct by seducing reputable scientists with financial incentives that make them beholden to corporate agendas.

Conclusions: Well-orchestrated assaults on science continue unabated and must now be met head-on. Success could be achieved by promoting and protecting the integrity of research. Furthermore, avoiding influence by conflicted corporate affiliates in occupational and public health regulations is needed. Identifying, managing and, ideally, eliminating corporate influence on science and science policy are needed to protect research integrity. Protecting the public's health, preventing disease, and promoting well-being must be the unambiguous goals of research in occupational and environmental health.

Keywords: Conflict-of-interest, Public health, Occupational health, Occupational diseases, Research integrity, Ethics, Policy, Public health regulations, Corporate influence

\footnotetext{
* Correspondence: baur@eomsociety.org

${ }^{1}$ University of Hamburg, Hamburg, Germany; European Society for

Environmental and Occupational Medicine, P.O. Box 370514, D-14135 Berlin,

Germany

Full list of author information is available at the end of the article
}

(c) The Author(s). 2019 Open Access This article is distributed under the terms of the Creative Commons Attribution 4.0 International License (http://creativecommons.org/licenses/by/4.0/) which permits unrestricted use, distribution, and reproduction in any medium, provided you give appropriate credit to the original author(s) and the source, provide a link to the Creative Commons license, and indicate if changes were made. The Creative Commons Public Domain Dedication waiver (http://creativecommons.org/publicdomain/zero/1.0/) applies to the data made available in this article, unless otherwise stated. 


\section{Our context}

Axiomatic to the question posed in this commentary is that objective knowledge gained through science helps to promote health and longevity. In addition, the freedom of scientists to conduct objective research and share the knowledge gained is essential to the advancement of science in the pursuit of truth.

In practice, the work products of occupational and environmental researchers provide important input to governmental decision-making and regulatory processes on matters pertaining to occupational, environmental and general public health. These researchers have a trusted role to play also in working with the media to inform and educate about scientific knowledge, as well as on the importance of independent science to both public health and safety.

All scientific research contributes to knowledge and must be in accord with the scientific method to be considered valid. Anything that interferes with adherence to the scientific method will serve to erode the integrity of science because anything but valid findings serve to undermine public trust in the role of science for advancing public policy. The integrity of the scientific method is best protected by exposing and blocking the undermining role of special interests that are incongruent with the public interest.

Without access to valid scientific evidence, those in the regulatory domain will not be able to make rational, informed decisions; each of health, safety, social justice, and environment are thereby placed in jeopardy. Derailing science in its pursuit of objective knowledge ultimately demeans science. In turn, the public-policy process and our democratic institutions are negatively impacted, as are the public's health and longevity. Through continuing education in research methods, ethics, and best practices, science is further advanced. In addition, education serves to hone the skills of scientists for detecting invalid science.

With conflicting roles and opinions between health scientists (e.g., physicians, practitioners, occupational and public health and biomedical researchers) and corporate interest groups (e.g., pharmaceutical, medical device, biotechnology, other industries and insurance companies) being widespread, media outlets are inclined to present opposing viewpoints. In this commentary, we show that a major source of conflict arises because the goals of for-profit companies include producing products that maximize financial returns to shareholders, while the goals of science include the pursuit of truth and the advancement of knowledge, in addition to maintaining and improving public health.

The goal of this commentary is to help expose and rout out invalid science by sensitizing scientists to those business influences that continue to undermine the pursuit of truth through the generation of invalid science.

\section{The scope of research integrity and conflict-of- interest (COI)}

Integrity in occupational and environmental health research, as in other scientific research, requires that the scientist adhere to the goal of pursuing truth. To achieve this, the scientist has a duty to be impartial throughout the process of addressing a research question. The research must not be compromised by special interests.

Providing unbiased knowledge to guide the protection of public health, and thus prevent disease and promote well-being, must be the unambiguous goal of all research and other activities in occupational and environmental medicine and public health. Any scientist who succumbs to influence that detracts from the principle of the pursuit of truth is, by definition, unethical by virtue of producing invalid scientific assessments that fail to serve the public interest, protect public health, or advance science and knowledge. This does not mean that funding from interested parties by itself undermines integrity; however, there is a high risk for bias when research is not well-designed, not properly analyzed, and not objectively interpreted as demonstrated to be the case when research is sponsored by business with financial interests. Consequently, influence has to be recognized and managed with a view to minimizing its impact; ideally, it should be eliminated.

Because of the public interest dimensions of the scientific enterprise, funded in part by the public purse, the United States Public Health Service in 1980 addressed the challenge of misconduct in science by establishing the Office of Research/Scientific Integrity. In their 2017 update, they define misconduct in science as "fabrication, falsification, or plagiarism (FFP) in proposing, performing, or in reporting research" [1]. See the corresponding definition and policy implementation by all US federal government agencies supporting intramural or extramural research through the Office of Science and Technology Policy 2000 [2]. A further category mentioned in the 1980 definition is that of "detrimental research practices", i.e. actions other than FFP. Actions such as selective publication and inappropriate analysis violate the traditional values of the research

Table 1 Criteria for Assessing the Severity of Conflict-of-Interest (from [55])

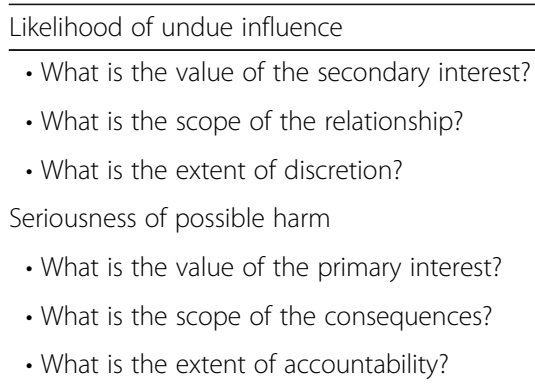


enterprise and are detrimental to the research process. Another dimension of misconduct is unacceptable behavior that is not unique to the research environment [3].

Malfeasance can arise when those engaged in science and regulatory processes are put into, or find themselves in a conflict-of-interest (COI) situation. The scientist who fails to acknowledge a COI and who knowingly proceeds to misuse and manipulate the scientific method to produce findings that support the interests of his/her sponsor, would be accused of malfeasance.

The risk of malfeasance arises when a secondary interest (such as that of personal financial gain) could adversely affect a primary interest (such as the duty to produce valid research). A COI may be financial (e.g. stock ownership, consulting fees) or non-financial (e.g. personal relationships) [4]. COI is not in itself a bias or a corrupt decision but, rather, a set of circumstances that poses a risk for primary obligations being compromised by succumbing - consciously or even subconsciously - to the influence of other interests. The existence of a COI does not imply that a scientist is improperly motivated; his/her perspective, however, may become biased.

Conflicts are not binary; that is, they are not simply either present or absent. A COI can be more or less severe and the seriousness of a conflict depends on the likelihood that scientists and physicians would be unduly influenced by a secondary interest and the degree of the harm or wrong that could result from such influence. See also Table 1 (below).

To minimize the impacts of COI on public health and to provide guidance for formulating and applying COI policies, a framework for analyzing conflicting interests is desirable.

\section{Our current reality}

The influence of industry on occupational, environmental, and public health research and practice has been well documented $[5,6]$. Corporate interests have frequently influenced science by an array of approaches [7]. Specifically, corporate interests influence research agendas and the design, conduct and dissemination of research through a variety of strategies (see Fig. 1).

\section{Influencing science policy}

One common method for influencing science policy arises when academic institutions are influenced through their pernicious pursuit of money and merge their interests with that of industry. Another most disturbing way that industry influences science is by its attempts to change the evaluation of science, particularly for its use in policy $[9,10]$. For example, the tobacco industry worked with established and existing business coalitions including the American Petroleum Institute, National Rifle Association, and the American Iron and Steel Institute to legislate changes in how research should be evaluated before it could be cited as evidence in support of a policy [11]. The American Chemistry Council works with politicians and regulators to develop policies that limit what science can be used to evaluate environmental pollutants. Also, through a careful read of the process followed, corporate interests shaped the Brussels Declaration on Ethics and Principles for Science and Society Policy-Making [12] to enhance the ability of industry to influence evidence and policy related to harm reduction. Thus, it surprises us that the Brussels Declaration received favourable support from key scientific organizations, including its launch at the American Association for the Advancement of Science and a letter in Nature.

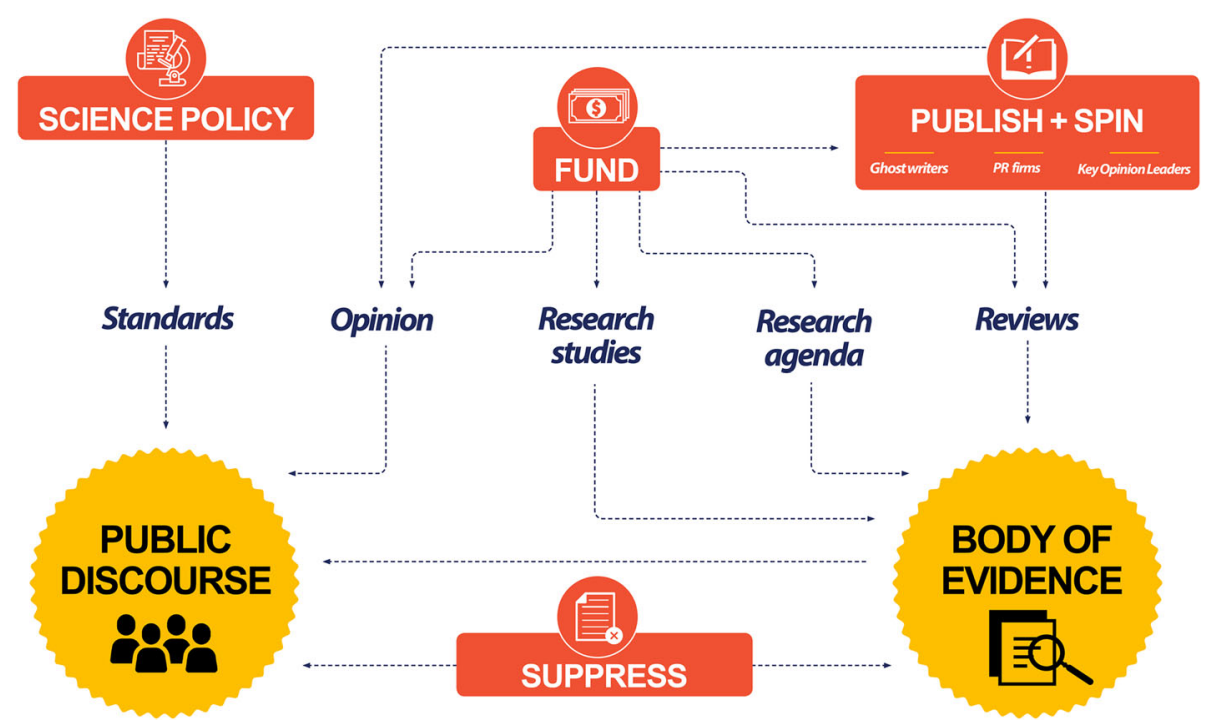

Fig. 1 Industry strategies to influence evidence and discourse about evidence ( [8] by courtesy of the author) 
Another important dimension of science policy malfeasance has arisen with the infiltration by vested interests of governmental decision-making bodies and regulatory processes for assessing hazards, risks and the need for preventive actions. Examples of such conduct include tobacco, asbestos, pollution, climate change and many other issues of commercial interest.

All these activities have been part of the industries' campaign to promote their version of 'sound science' and 'good epidemiology' [13-18]. In so doing, corporate interests frequently have inhibited or even blocked legislative solutions to ensure that public-policy is based on sound science [11, 17].

A well-studied example of corporate manipulation and malfeasance relates to the asbestos industry, along with their insurance companies, which for almost a century have influenced the results of scientific findings, delayed important knowledge about the asbestos-cancer relationship, and thereby influenced law and public policy to serve their own interests rather than the interests of workers and the public's health. Scientifically credible consultants were engaged to cast doubt on adverse health effects, diagnostic criteria and compensation issues; nowadays, the asbestos industry continues this influence $[15,19-24]$ by promoting the safe use of chrysotile asbestos which is not possible. Their strategy has successfully prevented its banning in various countries and its listing in the Rotterdam Convention declaration [25].

\section{Influencing research and scientific publication}

It is well known that COI has a strong influence on the outcome of research studies, thus shaping science to serve business interests [14, 26-29]. As reported by Friedman and Friedman [46], as well as by others $[18,30-32,52-55]$, in cases of financial COI, the proportion of findings supporting business interests differed significantly from studies without COI. Because of hidden ties, including ghost writing that cannot be identified, the real discrepancy can be assumed to be even greater. The chemical, pharmaceutical, car, nutrition and other industries have conducted research to $[14,33]$ deny, ignore or marginalize the adverse health effects caused by endocrine disrupting chemicals [30-32, 34], glyphosate/Round-up [35], various drugs [14, 33], sugar [36], and the recent dieselgate issue by broadly applied default devices [37, 38] .

A further approach is the systematic infiltration of the scientific literature and the media with biased science. This includes creating industry-driven scientific journals which can steer the perception of 'the evidence' by favoring studies that underplay or deny risk, giving supposed scientific credibility to editorials or biased reviews that can be used in litigation to defend industry and allow publication practices that bypass acceptance norms for scientific integrity. Detailed information on this aspect is available from the Toxic Docs website of the Columbia University and City University of New York [39] and includes the influence of publishers/journals, new forms of detrimental research practices such as the dismissal of journal editors engaged as health advocates for victims (example/ref. Wiley - D. Egilman [17, 40];), fake peer reviewing by some journal editors, and applying fake and predatory journalism with little or no editorial review or quality control of papers [41, 42]. Furthermore, groups wishing to bias research perception are using information technologies to manipulate how science is understood by consumers. See as an example tweet by President Donald Trump on 12:22-23. Aug. 2012 on "Massive combined inoculations to small children is the cause for big increase in autism...". https://twitter.com/realdonaldtrump/status/238717783 007977473

Obvious examples can be seen in:

- the manipulation of information technology in analysing research data to obtain desired results;

- globalizing a specific view of research findings through the use of "independent experts" commenting via social media, see for example the climate change and global warming issue as repeatedly presented by Donald Trump [43], and

- increasing the irrelevance of knowledge generated in certain fields to policy issues and political debates through a pervasive media environment that can help to generate unsound findings and controversies.

Another common tactic is to develop and disseminate public statements claiming that well-established facts are controversial. Several strategies have been adopted by entities with an economic interest in the outcome of health assessments to construct confusion by creating artificial controversy, for instance:

- Establishing principles of so-called 'good epidemiological practice' intentionally to be misused to dismiss studies that provide reliable evidence of harm as irrelevant for decision-making processes;

- Promoting impossibly difficult criteria for establishing causal relationships;

- Designing research which does not fit with the principles of sound science, resulting in manipulated research results; and

- Ignoring well-established knowledge on adverse health and/or environmental effects with highly selective interpretations of the literature [19, 31, 44]. 
Table 2 Case examples of industry efforts to influence glyphosate regulations [48]

\begin{tabular}{l}
\hline Applied measures to misinterprete science \\
\hline - Ghost-written research papers that assert glyphosate safety [35] \\
- Provided alternative interpretations of positive studies \\
- Used least statistically powerful tests on submitted research \\
- Developed a network of scientists to push glyphosate safety and \\
attack IARC \\
- Used public relations teams and others to increase political activity \\
and to attack the messenger (IARC, scientists, journalists, etc.) \\
- Provided EPA "talking points" about IARC classification \\
- Challenged two members of EPA's SAP and one was removed \\
- Enlisted EPA to block ATSDR review of glyphosate that they were \\
worried would agree with IARC. \\
- Drafted original Renewal Assessment Report for EFSA \\
- Exploited close relationships with journals, journalists and some \\
regulatory staff
\end{tabular}

\section{Influencing research agendas}

The increase in funding by vested interests reflects the ever-growing domination of the financial world in setting priorities for research. This can be a direct challenge to protecting human health. The relative lack of independent funding and/or lack of access to data poses grave dangers for the future of impartial research conducted in the public interest. This imbalance in funding between private and public sources creates a risk that many scientists in their search for funding make opportunistic or naïve compromises with industries that have an interest in particular research outcomes that support their products or activities [29, 33, 35, 45, 46]. It is not surprising that corporate interests should want to fund research to support their financial interests.

The glyphosate issue is a case example where science is misinterpreted [see Table 2 below].

\section{Further examples of industry strategies}

The strategies are broad. Some additional examples follow:

- offering scientists generous resources for research, but with restrictions on publication rights. This serves to absorb research capacity and control the results;

- paying scientists for consultancy and for representing industrial interests in science and policy fora often without disclosing their ties to industry;

- sponsoring pseudo-scientific think tanks, or special issues of journals that present the findings of a series of manipulated studies; and
- conducting ad hominem attacks on scientists who have published findings suggesting hazardous associations with industry products or processes.

The intent of the aforementioned corporate activities - in decision-making processes for assessing hazards, risks and the need for preventive actions regarding among others, tobacco, asbestos, benzene, diesel exhaust, plastics, pesticides, climate change - is to promote selfinterest regardless of the cost to the public's health. One of the best example is the tobacco industry which has backed a number of 'astroturf initiatives to attempt to influence regulation [48]. Far too often, early warnings of occupational and environmental hazards are intentionally delayed or dismissed through being able to maintain the status quo and protect business interests.

\section{Why and how to assess and evaluate COI}

Complete and accurate disclosure of financial ties with corporate interests, which is still frequently lacking, is a critical first step to routing out influence in the advancement of knowledge. This would make more transparent the forces of both bias and influence in science.

When conflicts of interest are made transparent, they should be assessed by considering various factors that determine their likelihood and seriousness. Likelihood depends on the value of the secondary interest, the scope of the relationship between the professionals and the commercial interests, and the extent of discretion that the professionals have (Table 1). Seriousness depends on the value of the primary interest, the scope of the consequences that affect it, and the extent of accountability of the professionals. COI policies should be evaluated by considering their effectiveness, transparency, accountability, and fairness in order to deal with such conflicts appropriately [55] (Table 3).

A better understanding of the nature of $\mathrm{COI}$ and a clearer and fairer formulation of rules could support greater confidence in medical and scientific advice and thereby enable researchers to concentrate on their primary missions of conducting and publishing unbiased research.

\section{How to address the continued undermining of integrity in science and $\mathrm{COI}$}

Sound science using policy-making processes and regulations has the potential to solve occupational and environmental health problems, and to impact society in a more sustainable way. Physicians, practitioners, public health and biochemical researchers, advocate based on their credibility. They thus have the duty to speak out on this issue with students, colleagues, peers, in the professional arena (including the scientific literature) and, through the media, to the public. 
Table 3 Criteria for evaluating conflict-of-interest policies (from [55])

\begin{tabular}{ll}
\hline Criterion & Description \\
\hline Proportionality & Is the policy most efficiently directed at the most important conflicts? \\
Transparency & Is the policy comprehensible and accessible to the individuals and institutions that may be affected by the policy? \\
Accountability & Does the policy indicate who is responsible for enforcing and revising it? \\
Fairness & Does the policy apply equally to all relevant groups within an institution and in different institutions? \\
\hline
\end{tabular}

A major problem is that scientists are frequently not aware of underlying processes and/or are not willing to take part in the time-consuming and cumbersome work of addressing scientific integrity. As stressed by Agerstrand et al. [56], actions for increased understanding about science-policy interactions are urgently needed. These include the reporting of studies in a way that enables their regulatory use, submitting studies and comments on current sociopolitical assessment and processes, dialogues with stakeholders and policy-makers, as well as training the next generation of scientists in public health. A systemic approach addressing perverse incentive structures within universities and editorial boards and a shift towards a rights-based paradigm with genuine stakeholder involvement are recommended [57].

\section{Principles for safeguarding the integrity of research in occupational and environmental health}

The following steps have been proposed to decrease and expose the influence of financial conflicts of interest on the integrity of research in occupational and environmental health and to help inform policy-makers [58]:

\section{Conflict-of-interest declarations}

COI declaration should focus on declarations of financial resources for the research activity, and on any relevant connection of the researchers with industry that might have a financial interest in the outcomes of the study. Effective enforceable disclosure policies including penalties for not disclosing accurately must play an important role in protecting peer review journals, peer review panels, and government entities against becoming unwitting agents of misinformation. However, effective COI disclosure policies are necessary, but are not in themselves sufficient.

\section{Scientists' ethical constraints}

Ethical constraints of research and the evaluation of the respect of these ethical principles should equally apply to all research activities in the field of occupational and environmental health, no matter who initiates, conducts or finances it. Failure to enforce ethical principles is not acceptable.

\section{Funding}

It is the responsibility of governments to foster the conduct of impartial research of which the primary goal is to discover and communicate relevant evidence on factors affecting workers and population health. Failure to promote such efforts will adversely affect decisionmaking policies and practices in occupational and environmental health. The creation of independent research funds to which industry must contribute may be a partial solution to this problem.

\section{Decision-making processes}

It is not possible to eliminate the production of all bad science. But it is possible to prevent the use of the outcomes of bad science in decision-making processes and in assessments of health hazards and risks. Fairly evaluating published research in the process of peer-review is becoming increasingly challenging in a world that is characterized by infiltration of powerful interests at all levels of science [60]. Applying the principle of COI declaration for every person involved at each level of decision-making may create the necessary transparency to identify and address distortions by the regulated community. Research evidence that is used to inform policy should be evaluated according to criteria that are the consensus of the independent scientific community, and not the industry being evaluated.

\section{Restoring dignity in academic publishing}

The rise of predatory publishing without quality standards and with commercial interests represents a severe threat to the scientific community and to those who rely on the assumed validity of scientific findings. To preserve the integrity and dignity of being a scientist, every researcher, clinician, academic and professional should scrutinize the journals cited and to which publications are submitted [61].

The Collegium Ramazzini [58], an independent, international academy with internationally renowned experts in the fields of occupational and environmental health, called for the following detailed actions:

- National and international official bodies to set up evaluation procedures that systematically orient funding towards research centers, researchers and research activities with demonstrated commitment 
to competence and impartiality in assessing health effects.

- Governments to operationalize the Right to Enjoy the Benefits of Scientific Progress, as contained in the International Covenant on Social, Economic and Cultural Rights by promoting science of the highest ethical standard as a public good. That right implies an obligation on government entities to create a research environment in which unbiased and relevant scientific knowledge is advanced and disseminated without obstacle. Efforts to reinterpret science or assessments of it in a biased way that apparently favours economically and politically vested interests could be interpreted as an interference with that right. Public policy-makers and the public can benefit from science only if it is allowed to be conducted, assessed, and communicated in an unbiased way. States should also ensure transparency in funding of research through mandating open declaration of sources of funding when research is proposed, disseminated, and presented.

- Scientific journals to establish mechanisms, consistent with international best practices that provide disciplinary action for editors, authors and peer reviewers who fail to disclose financial conflicts and competing interests [28]. In the absence of effective implementation, policies mean little.

- All public institutions that play a role in risk assessment and public health policies to systematically rely upon the advice that is transparent, credible and subject to public scrutiny.

- All decision-making bodies to set up effective COI disclosure policies for all persons involved in the process.

- The scientists involved in occupational and environmental health to never divert from the path of scientific integrity in their scientific research, assessments and communications, and that they consistently strive for objectivity, impartially pursue scientific truth and eliminate financial and other COIs, with a view to public health protection.

- The Collegium Ramazzini encourages scientists to contact the Collegium when their independence is threatened in a way that puts a burden on their freedom to consistently follow that path.

- The Collegium Ramazzini calls on all professional bodies to support scientists who are under threat for speaking the truth.

Similarly, according to A Consensus Study Report of the National Academies of Sciences, Engineering, Medicine [1] the following activities are needed:
- all professionals in public health should significantly improve and update their practices and policies to respond to the threats to research integrity;

- research institutions should maintain the highest standards for research conduct;

- research institutions and federal agencies should work to ensure that whistle-blowers are protected and that their concerns are assessed and addressed in a fair, thorough, and timely manner;

- a research integrity advisory board should be established as an independent not-for-profit organization;

- societies and journals should develop clear disciplinary authorship standards;

- research sponsors and science, engineering, technology and publishers should ensure that information sufficient for a person knowledgeable about the field and the techniques to reproduce reported results is made available;

- federal funding agencies and other research sponsors should allocate sufficient funds to enable the longterm storage, archiving and access of datasets necessary for the replication of published findings;

- researchers should routinely disclose all statistical tests carried out, including negative findings;

- governmental agencies and private foundations should fund research to quantify, and develop responses to, conditions in the research environment that may be linked to research misconduct and detrimental research practices;

- researchers, research sponsors, and research institutions should continue to develop and assess more effective education and other programs that support the integrity of research; further, they should leverage these partnerships to force the research through mutual learning and sharing of best practice.

Finally, those engaged in decision-making processes relating to environmental and occupational exposures should argue systematically for decisions that protect the most vulnerable and sensitive in society, such as children and pregnant women. Protecting the most vulnerable in society protects all and, besides, it is the responsibility of those in public health to advocate for those without a voice.

\section{What this commentary recognizes}

Because, as David Michaels has noted, corporations provide "science for hire, period, and it is extremely lucrative" [29], in this commentary we bring attention to the undermining of occupational and environmental global public health through the insertion of "knowledge" through mechanisms of deliberate corporate manipulation that we 
label as malfeasance. Practices of corporate malfeasance include:

- Contamination of editorial boards of peer-reviewed scientific journals with industry apologists resulting in the publication of poorly-designed research studies that produce some biased results that mislead readers and flood the literature with invalid science;

- Interference with the activities of national regulatory bodies (e.g. USEPA, EFSA) and international review panels (e.g. WHO/IARC) and other independent organizations engaged in safeguarding occupational and public health;

- Constructing roadblocks, e.g. by capitalizing on uncertainty to undermine scientific consensus for much-needed government regulation of carcinogenic, endocrine-disrupting and/or immunotoxic agents widely present in the workplace and the environment, including air toxics, pesticides and toxic metals;

- The promotion of "causation" criteria that lack foundation and effectively block workers' access to legal remedies for harms from occupational exposures resulting in morbidity and premature mortality.

- Violating standards of professional conduct by seducing reputable scientists with financial incentives that make them beholden to serve the corporate agenda.

This well-orchestrated assault on science must be met head-on and could be achieved by promoting and protecting the integrity of research. Further, avoiding influence by conflicted corporate affiliates in occupational and public health regulations would be needed. In so doing, the welfare of patients and society through quality medical and public health research and education would be more assured.

\section{Conclusions}

The primary goals of medicine and public health activities are to:

- improve public health by fostering preventive strategies and providing beneficial care to patients and the public;

- conduct valid research;

- give advice to governmental decision-making bodies and in regulatory processes; and

- offer excellent medical and scientific education.

From the policy perspective, relevant scientific evidence comprises studies that are valid and sufficiently reliable. In pursuing these goals, individual professionals, health care institutions, and research organizations have obligations to put public health, workers and patient interests first, carry out unbiased research, critically appraise information, and serve as good role models of professional behavior for students.

Corporate interests have frequently influenced science by driving research agendas, manipulating the design, methods and conduct of research, and selectively publishing findings or affecting the interpretation of findings $[7,50]$. Conflicting interests arise because, in many circumstances in modern medicine and public health, these goals and obligations are at risk of being compromised by the interest of financial gain.

Concern has also to be expressed owing to the fact that scientific integrity is frequently violated through research that is supported by individuals or corporations with conflicting interests, whose primary goal is often to protect markets for products or pollutants which have hazardous potential. The impact of corrupted science on subverting legislation, and in undermining policy-making, standardsetting and legal proceedings, is seen with greater frequency. This trend should alarm authorities, workers, consumers and the public at large.

Malfeasance has to be met by promoting and protecting the integrity of research, the welfare of patients and society, and the quality of medical and research education. Important measures are: open access to data, rigorous methodological standards, disclosure of conflicting interests and acknowledgement of bias in order to align with the principles of research integrity that are normative among researchers. Thus, academics, and public health researchers and practitioners should be alert to supporting industry initiatives disguised as ways to promote research integrity [9].

Effective strategies to avoid personal COIs are needed. These include the elimination of secondary interests, accompanied by prevailing full transparency, fairness, proportionality and accountability. Physicians and scientists involved in occupational and environmental health should never divert from the path of scientific integrity, assessments and communications. They should consistently strive for objectivity by impartially pursuing scientific truth with a view to public health protection.

\section{Abbreviations}

COI: Conflict-of-interest; EFSA: European Food Safety Authority; EPA / USEPA: United States Environmental Protection Agency; FFP: Fabrication, falsification, or plagiarism; IARC: International Agency for Research on Cancer; SAP: Scientific Advisory Panel; WHO: World Health Organization

\section{Acknowledgements}

The authors appreciate the opportunity given at the 2018 Ramazzini Days for a panel entitled "Corporate influence threatens the public's health". This commentary has been greatly improved thanks to the thoughtful and critical input of four external reviewers. 


\section{Authors' contributions}

$\mathrm{XB}$ developed the concept of this manuscript and wrote the first draft. CLS and $L B$ critically revised it and provided many substantial contributions and amendments. CLS also did final editing and writing. All authors have read and approved the final version.

\section{Funding}

No funding was provided.

\section{Ethics approval and consent to participate}

There were no study participants.

\section{Competing interests}

The authors declare that they have no competing interests.

\section{Author details}

'University of Hamburg, Hamburg, Germany; European Society for Environmental and Occupational Medicine, P.O. Box 370514, D-14135 Berlin Germany. ${ }^{2}$ University of Alberta, School of Public Health, 3-300 Edmonton Clinic Health Academy, 11405 - 87 Avenue, Edmonton, AB T6G 1C9, Canada. ${ }^{3}$ Health Research Institute, University of Canberra, Canberra, Australia. ${ }^{4}$ Medicines Use and Health Outcomes, The University of Sydney, Charles Perkins Centre, D17, The Hub, 6th floor, Sydney, NSW 2006, Australia.

Received: 4 June 2019 Accepted: 22 September 2019

\section{Published online: 04 November 2019}

\section{References}

1. The National Academies of Sciences E, Medicine. Fostering Integrity in Research. Washington, D.C.: The National Academies Press; 2017. Available from: https://www.nap.edu/read/21896/chapter/1

2. Office of Science and Technology Policy. Federal research misconduct policy. Fed Regist. 2000;65(235):76260-4.

3. National Academy of Sciences National Academy of Engineering, and Institute of Medicine Panel on Scientific Responsibility and the Conduct of Research: Responsible Science: Ensuring the Integrity of the Research Process. Washington, DC, USA: National Academy Press; 1992. Accessed 29 Aug 2019]. Available from: https://www.ncbi.nlm.nih.gov/books/NBK234523/.

4. Bero LA, Grundy $\mathrm{Q}$. Why having a (nonfinancial) interest is not a conflict of interest. PLoS Biol. 2016;14(12):e2001221.

5. Bero LA. Tobacco industry manipulation of research. Public Health Rep. 2005;120(2):200-8.

6. White J, Bero LA. Corporate manipulation of research: strategies are similar across the industry. Stan L Pol'y Rev. 2010;21:105-34.

7. Odierna DH, Forsyth SR, White J, Bero LA. The cycle of bias in health research: a framework and toolbox for critical appraisal training. Account Res. 2013;20(2):127-41

8. Moynihan R, Macdonald H, Heneghan C, Bero L, Godlee F. Commercial interests, transparency, and independence: a call for submissions. Bmj. 2019;365:11706.

9. Bero L. Ten tips for spotting industry involvement in science policy. Tob Control. 2019;28(1):1-2

10. Apollonio DE, Bero LA. Interpretation and use of evidence in state policymaking: a qualitative analysis. BMJ Open. 2017;7(2):e012738.

11. Baba A, Cook DM, McGarity TO, Bero LA. Legislating "sound science": the role of the tobacco industry. Am J Public Health. 2005:95(Suppl 1):S20-7.

12. Ethics \& Principles for Science \& Society Policy-Making - The Brussels Declaration2017 Accessed 28 Aug 2019. Available from: http://www.sci-com. eu/main/docs/Brussels-Declaration.pdf

13. McCambridge J, Daube M, McKee M. Brussels declaration: a vehicle for the advancement of tobacco and alcohol industry interests at the science/ policy interface? Tob Control. 2019;28(1):7-12.

14. Axelson O, Balbus JM, Cohen G, Davis D, Donnay A, Doolittle R, et al. Re: regulatory toxicology and pharmacology. Int J Occup Environ Health. 2003; 9(4):386-9 author reply 9-90.

15. Egilman DS, Bird T, Lee C. MetLife and its corporate allies: dust diseases and the manipulation of science. Int J Occup Environ Health. 2013;19(4): 287-303.

16. Egilman D, Bird T, Lee C. Dust diseases and the legacy of corporate manipulation of science and law. Int J Occup Environ Health. 2014;20(2):115-25.

17. Greenberg DS. Science, money, and politics: political triumph and ethical erosion. Chicago: The University Chicago Press; 2001.
18. Baur X, Budnik LT, Ruff K, Egilman DS, Lemen RA, Soskolne CL. Ethics, morality, and conflicting interests: how questionable professional integrity in some scientists supports global corporate influence in public health. Int J Occup Environ Health. 2015;21(2):172-5.

19. Baur X, Soskolne CL, Lemen RA, Schneider J, Woitowitz HJ, Budnik LT. How conflicted authors undermine the World Health Organization (WHO) campaign to stop all use of asbestos: spotlight on studies showing that chrysotile is carcinogenic and facilitates other non-cancer asbestos-related diseases. Int J Occup Environ Health. 2015;21(2):176-9.

20. Pezerat H. Chrysotile biopersistence: the misuse of biased studies. Int J Occup Environ Health. 2009:15(1):102-6.

21. Bohme SR. Expression of concern: false claim to be free of conflicts in asbestos biopersistence debate. Int J Occup Environ Health. 2012;18(2):85-8.

22. Egilman D, Fehnel C, Bohme SR. Exposing the "myth" of ABC, "anything but chrysotile": a critique of the Canadian asbestos mining industry and McGill University chrysotile studies. Am J Ind Med. 2003;44(5):540-57.

23. Woitowitz HJ, Baur X. Misleading "new insights into the Chrysotile debate". Pneumologie. 2018;72(7):507-13.

24. Oliver LC, Belpoggi F, Budnik LT, Egilman D, Frank AL, Mandrioli D, et al. Correspondence regarding the article "The asbestos fibre burden in human lungs: new insights into the chrysotile debate". Eur Respir J. 2017;50(6). https://www.ncbi.nlm.nih.gov/pubmed/29269580. https://doi.org/10.1183/ 13993003.01644-2017. Print 2017 Dec.

25. Ruff K. Asbestos industry sabotages UN Rotterdam Convention https:// rightoncanada.ca/?p=4027May 4, 2017 Accessed 28 Aug 2019.

26. Sass JB, Castleman B, Wallinga D. Vinyl chloride: a case study of data suppression and misrepresentation. Environ Health Perspect. 2005;113(7):809-12.

27. Mandrioli D, Kearns CE, Bero LA. Relationship between research outcomes and risk of Bias, study sponsorship, and author financial conflicts of interest in reviews of the effects of artificially sweetened beverages on weight outcomes: a systematic review of reviews. PLoS One. 2016;11(9):e0162198.

28. Amsterdam JD, McHenry LB, Jureidini JN. Industry-corrupted psychiatric trials. Psychiatr Pol. 2017;51(6):993-1008.

29. Michaels D. Doubt is their product: how industry's assault on science threatens your health. New York: Oxford University Press; 2016

30. Grandjean P, Ozonoff D. Transparency and translation of science in a modern world. Environ Health. 2013:12(1):70

31. Bergman A, Andersson AM, Becher $G$, van den Berg M, Blumberg B, Bjerregaard $\mathrm{P}$, et al. Science and policy on endocrine disrupters must not be mixed: a reply to a "common sense" intervention by toxicology journal editors. Environ Health. 2013;12:69.

32. Bergman A, Heindel JJ, Kasten T, Kidd KA, Jobling S, Neira M, et al. The impact of endocrine disruption: a consensus statement on the state of the science. Environ Health Perspect. 2013;121(4):A104-6.

33. Fabbri A, Grundy Q, Mintzes B, Swandari S, Moynihan R, Walkom E, et al. A cross-sectional analysis of pharmaceutical industry-funded events for health professionals in Australia. BMJ Open. 2017;7(6):e016701.

34. Begley S. Insight: Science for hire - Trial over plastic exposes disclosure deficit. Science News. 2013. Accessed 29 Aug 2019. Available from: https:/www.reuters. com/article/us-science-eastmanchemical-insight/insight-science-for-hire-trial-overplastic-exposes-disclosure-deficit-idUSBRE96H05020130718.

35. McHenry LB. The Monsanto papers: poisoning the scientific well. Int J Risk Safety Med. 2018;29(3-4):193-205.

36. Kearns CE, Apollonio D, Glantz SA. Sugar industry sponsorship of germ-free rodent studies linking sucrose to hyperlipidemia and cancer: an historical analysis of internal documents. PLoS Biol. 2017; 15(11):e2003460

37. Stanford Professors Sue Volkswagen, Allege Emissions "Defeat Device" May Have Come From Silicon Valley. NBC Bay Area [Internet]. 2015. Accessed 29 Aug 2019.

38. Amelang S, Wehrmann B. "Dieselgate" - a timeline of Germany's car emissions fraud scandal. Clean Energy Wire CLEW. 2019 Accessed 29 Aug 2019. Available from: https://www.cleanenergywire.org/factsheets/ dieselgate-timeline-germanys-car-emissions-fraud-scandal.

39. Chowkwanyun M, Markowitz G, Rosner D. Toxic docs: version $1.0 \mathrm{https} / / /$ www.toxicdocs.org/ Accessed 28 Aug 2019. New York: Columbia University and City University of New York; 2018.

40. Starr D. Expert witness David Egilman wins billions—and makes enemies - as he fights companies over public health. Science Magazine. 2019. Accessed 29 Aug 20019. Available from: https://www.sciencemag.org/ 
news/2019/01/expert-witness-david-egilman-wins-billions-and-makesenemies-he-fights-companies-over.

41. Hemmat EM, Wongwises S, Asadi A, Akbari M. Fake journals: their features and some viable ways to distinguishing them. Sci Eng Ethics. 2015;21:821-4.

42. Richtig G, Berger M, Lange-Asschenfeldt B, Aberer W, Richtig E. Problems and challenges of predatory journals. J Eur Acad Dermatol Venereol. 2018;32(9):1441-9.

43. Miller B. Trump tweets climate change skeptic in latest denial of science. https:/edition.cnn.com/2019/03/12/us/trump-climate-change-tweet-patrickmoore/index.html. CNN Accessed 28 Aug 2019 edMarch 19, 2019.

44. Greenberg SA. How citation distortions create unfounded authority: analysis of a citation network.BMJ. 2009;339:b2680. https://www.bmj.com/ content/339/bmj.b2680.

45. Krimsky S. Combating the funding effect in science: what's beyond transparency? Stan L Pol'y Rev. 2010;21:101-23.

46. Friedman L, Friedman M. Financial conflicts of interest and study results in environmental and occupational Health Research. J Occup Environ Med. 2016;58(3):238-47.

47. Apollonio D, Bero L. The creation of industry front groups: the tobacco industry and "get government off our Back". Am J Public Health. 2007; 97(3):419-27.

48. Portier CJ. Experiences with glyphosate regulations worldwide: pressures from industry versus human health. Eur J Oncol. 2018;23(3):124.

49. Michaels D. Doubt is their product how Industrys assault on science threatens your health. New York: Oxford University Press; 2016.

50. Michaels D. Manufactured Uncertainty: Protecting Public Health in the Age of Contested Science and Product Defense; 2006. p. 149-62.

51. Hardell L, Walker MJ, Walhjalt B, Friedman LS, Richter ED. RE: a rebuttal: secret ties to industry and conflicting interests in cancer research. Am J Ind Med. 2007;50(9):697-8 author reply 9-700.

52. Hardell L, Walker MJ, Walhjalt B, Friedman LS, Richter ED. Secret ties to industry and conflicting interests in cancer research. Am J Ind Med. 2007;50(3):227-33.

53. Bekelman JE, Li Y, Gross CP. Scope and impact of financial conflicts of interest in biomedical research: a systematic review. JAMA. 2003; 289(4):454-65.

54. Kjaergard LL, Als-Nielsen B. Association between competing interests and authors' conclusions: epdemiological study of randomised clinical trials published in BMJ. BMJ Case Reports. 2002;325(7358):249.

55. Lo B, Field MJ. Principles for identifying and assessing conflicts of interest. In: conflict of interest in medical research, education, and practice. Washington, D.C.: The National Pcademies press; 2009.

56. Agerstrand M, Sobek A, Lilja K, Linderoth M, Wendt-Rasch L, Wernersson AS, et al. An academic researcher's guide to increased impact on regulatory assessment of chemicals. Environ Sci Process Impacts. 2017;19(5):644-55.

57. Cosgrove L, Peters SM, Vaswani A, Karter JM. Institutional corruption in psychiatry: case analyses and solutions for reform. Soc Personal Psychol Compass. 2018;12(6):e12394.

58. Collegium Ramazzini. Principles for Safeguarding the Integrity of Research In Occupational and Environmental Health.2018 Accessed 28 Aug 2019. Available from: http://www.collegiumramazzini.org/download/2017_10_20_ Unpublished_Integrity_Statement.pdf.

59. Collegium Ramazzini. Principles for Safeguarding the Integrity of Research In Occupational and Environmental Health. http://www.collegiumramazzini. org/publications.asp/2018. Accessed 29 Aug 2019.

60. Shawwa K, Kallas R, Koujanian S, Agarwal A, Neumann I, Alexander P, et al. Requirements of clinical journals for Authors' disclosure of financial and non-financial conflicts of interest: a cross sectional study. PLoS One. 2016; 11(3):e0152301.

61. Shapiro SB, Franco EL. Restoring dignity in academic publishing is a collective duty. JDR Clin Trans Res. 2019;4(1):5-8.

\section{Publisher's Note}

Springer Nature remains neutral with regard to jurisdictional claims in published maps and institutional affiliations.

Ready to submit your research? Choose BMC and benefit from:

- fast, convenient online submission

- thorough peer review by experienced researchers in your field

- rapid publication on acceptance

- support for research data, including large and complex data types

- gold Open Access which fosters wider collaboration and increased citations

- maximum visibility for your research: over $100 \mathrm{M}$ website views per year

At BMC, research is always in progress.

Learn more biomedcentral.com/submissions 